\title{
Myocardial T1 mapping as a diagnostic tool in pediatric patients with a concern for cardiac disease
}

\author{
Cory V Noel ${ }^{1 *}$, Ramkumar Krishnamurthy ${ }^{2}$, Rajesh Krishnamurthy ${ }^{2}$ \\ From 19th Annual SCMR Scientific Sessions \\ Los Angeles, CA, USA. 27-30 January 2016
}

\section{Background}

Myocardial tissue characterization with both native T1 mapping and T1 mapping following gadolinium based contrast agents ( $\mathrm{T} 1$ enhanced) has emerged as an important asset of CMR imaging [1]. However, there is only minimal experience in pediatrics [2]. Native T1 has shown to be a marker of myocardial edema, and may play a role in pathologic states such as myocarditis [3]. T1 enhanced mapping has shown to be a useful biomarker for disease sates with diffuse fibrosis, such as hypertrophic cardiomyopathy (HCM), and is comparable to myocardial biopsy [4].

Purpose: To examine the effectiveness of CMR myocardial characterization by native $\mathrm{T} 1$ and $\mathrm{T} 1$ enhanced mapping in a heterogenous group of pediatric patients with signs concerning for cardiomyopathy or myocarditis.

\section{Methods}

We reviewed our initial experience of an ongoing study with T1 mapping in 10 subjects (aged $15.4 \pm 2.5$ years). All patients underwent CMR due to signs suggestive of cardiac disease. Cohort included 4 patients with concern for myocarditis, 4 with concerns for HCM, and 2 with concern for myocardial ischemia. 3 of the acquisitions were made in $3 \mathrm{~T}$ Acheiva ${ }^{\mathrm{TM}}$, remainder used 1.5T Ingenia $^{\mathrm{TM}}$ scanner (Philips Healthcare, Best Netherlands).

Acquisition Protocol: All clinically indicated MRI sequences were performed, including delayed enhanced phase sensitive inversion recovery sequence, after injection of contrast (Magnevist ${ }^{\mathrm{TM}}$ ). T1 mapping (modified Look Locker - MOLLI) sequence was performed prior to contrast injection and post contrast (15 minutes after contrast) injection. The MOLLI sequence had a bSSFP readout TR $/ \mathrm{TE} / \alpha=3 / 1.5 \mathrm{~ms} / 20^{\circ}$; A 5,5,3 inversion acquisition scheme was used, and acquisition time was 13 heart beats.

\section{Data Analysis}

The T1 was measured by manually drawing a region of interest at both the interventricular septum and the free wall after exporting the data to a custom made Matlab ${ }^{\mathrm{TM}}$ program. Pixels with a zero value - representing a noisy T1 fit were ignored from the calculations.

\section{Results}

The native and enhanced T1 were calculated for all patients except 1 who had significant artifact in the free wall on the native T1 sequence. The 2 patients with concern for myocardial ischemia, and 1 patient with possible HCM were assessed on the 3T. As assessed on the 1.5T, the native $\mathrm{T} 1$ of the free wall in patients who were clinically treated for myocarditis $(\mathrm{n}=3)$ was significantly higher than the native T1 in all other patients $(\mathrm{n}=4)$, $1094 \pm 38 \mathrm{~ms}$ vs. $986 \pm 23 \mathrm{~ms}(\mathrm{p}<0.05)$. Likewise, the septal T1 enhanced of patients who were diagnosed with $\operatorname{HCM}(\mathrm{n}=3)$ was lower than the remaining patients $(\mathrm{n}=4), 460 \pm 16 \mathrm{~ms}$ vs. $533 \pm 16 \mathrm{~ms}(\mathrm{p}<0.05)$.

\section{Conclusions}

Myocardial characterization may be an effective tool in pediatric patients with a potential diagnosis of cardiomyopathy or myocarditis. Within a heterogenous group of patients, the native $\mathrm{T} 1$ was able to distinguish myocarditis from other potential cardiac disorders, while the enhanced T1 was able to distinguish HCM.

\section{Authors' details \\ ${ }^{1}$ Pediatric Cardiology, Baylor College of Medicine, Houston, TX, USA. \\ ${ }^{2}$ Radiology, Texas Children's Hospital, Houston, TX, USA.}

Published: 27 January 2016 


\section{References}

1. J CMR 16:2

2. Circ Imaging , 2: e002504.

3. JACC Imag 8:1.

4. Radiology $256: 3$

doi:10.1186/1532-429X-18-S1-P167

Cite this article as: Noel et al:: Myocardial T1 mapping as a diagnostic tool in pediatric patients with a concern for cardiac disease. Journal of Cardiovascular Magnetic Resonance 2016 18(Suppl 1):P167.

Submit your next manuscript to BioMed Central and take full advantage of:

- Convenient online submission

- Thorough peer review

- No space constraints or color figure charges

- Immediate publication on acceptance

- Inclusion in PubMed, CAS, Scopus and Google Scholar

- Research which is freely available for redistribution 